STUDIA ROMANICA POSNANIENSIA

UAM $\quad$ Vol. 40/2 Poznań 2013

\author{
BARBARA ŁUCZAK \\ Universidad Adam Mickiewicz de Poznań \\ basia@amu.edu.pl
}

\title{
CIUDAD Y TEXTO: LEYENDO A MONTSERRAT ROIG EN COMPAÑÍA DE CRISTINA DE PIZÁN
}

\begin{abstract}
Barbara Łuczak, Ciudad y texto: leyendo a Montserrat Roig en compañía de Cristina de Pizán [City and text: reading Montserrat Roig with Christine de Pizan at your side], Studia Romanica Posnaniensia, Adam Mickiewicz University Press, Poznań, vol. XL/2: 2013, pp.105-117. ISBN 978-83232-2597-3. ISSN 0137-2475. eISSN 2084-4158.

In the article we study two visions of the city. A "classical" and allegorical one is included in Christine de Pizan's well-known oeuvre, Le Livre de la Cité des Dames (1404/1405). We compare it to a biographically conditioned construction from the essays Digues que m'estimes encara que sigui mentida (1991) by the Catalan writer Montserrat Roig. The key factor in our analysis is the chronotope structure and the relationship between the image of the city and the writing act. We note a number of similarities between the two visions, some of them stemming from the identity and the social and cultural situation of the feminine subject, but also point out some differences, as those determined by the historical context of both texts and their literary genres.
\end{abstract}

Keywords: Catalan literature, Montserrat Roig, city, chronotope, Christine de Pizan, women's writing

El 23 de enero de 1991 los lectores del diario Avui encontraban estas palabras en la columna redactada por Montserrat Roig:

Christine de Pizan escrivia el 1405: «I també, certament, Déu ha donat la paraula a les dones. I lloat sigui! Perquè, si no ho hagués fet, serien mudes». La dama d'origen italià i educada a França, i que des dels 25 anys va haver de mantenir la mare i tres fills exercint el difícil, i sovint no gaire satisfactori, ofici d'escriure, deixa anar aquestes paraules a La ciutat de les dames, que ara podeu llegir gràcies a Edicions l'Eixample i amb una excel·lent traducció de Mercè Otero i Vidal. Christine era una dona entenimentada i estava una mica farta de l'abundosa literatura misògina que, a la seva època i també abans, tenia un gran èxit i difusió. [...] Una mica farta, doncs, de judicis que tenien prestigi però que no havien estat gaire comprovats. La dama Christine decideix de construir una ciutat per a les dones. La raó l'ajuda en els fonaments, la rectitud l'ensenya a aixecar els edificis i, en acabat, la justícia li diu, a Christine, quines seran les dones, nobles de cor i rectes d'enteniment, que habitaran la ciutat (Roig, 1992: 165-166).

Estas palabras, apuntadas bajo el título "Imaginem-nos una cultura de la pau", Montserrat Roig las escribía durante la Guerra del Golfo Pérsico, consciente de que Cristina de Pizán había redactado Le Livre de la Cité des Dames, su obra más conocida 
y celebrada, durante otro conflicto bélico, la Guerra de los Cien Años. Frente a una "cultura de la guerra", espectacular y rentable, Roig se imaginaba una cultura de la paz, "pobra, lenta i silenciosa", que "basteix ciutats dins el somni" (1992: 166-167). A la vez recomendaba la traducción catalana de la obra maestra de Cristina de Pizán, que se acababa de publicar, preparada por Mercè Otero i Vidal (Pizán, 1990); cinco años más tarde vería luz la versión castellana del libro, elaborada por Marie-José Lemarchand (Pizán, 1995)1.

En aquel mismo 1991, año de su muerte, Montserrat Roig entregaba en manos de los lectores el volumen Digues que m'estimes encara que sigui mentida. Sobre el plaer solitari d'escriure i el vici compartit de llegir. En él se incluía junto con otros escritos el ensayo "De finestres, balcons i galeries" en el que la escritora abordaba el tema de la experiencia femenina de la ciudad y del espacio público (o de la ciudad considerada como espacio público). El ensayo se divide en dos partes. La primera consta de cuatro apartados que forman una unidad (el primero lleva el título "Domus amica, domus optima"). A continuación, como una suerte de coda, aparece añadido un texto en gran medida independiente titulado "Barcelona, una geografia literària". En la primera parte del ensayo, Roig esboza una serie de cuadros de la historia de Barcelona protagonizados por mujeres que en diferentes períodos miran la ciudad. Son: una mujer del siglo XIV, una dama del siglo XVII, una "chinche" del siglo XIX y burguesas de finales del siglo XIX y del siglo XX. "Barcelona, una geografia literària" tiene un componente autobiográfico más marcado: en esta parte se presentan recuerdos de la infancia y la juventud de la escritora. Considerado en su totalidad, "De finestres, balcons i galeries" es una visión personalísima de las relaciones que la mujer ha mantenido con el espacio público y urbano en diferentes momentos históricos y del desarrollo de Barcelona y la sociedad catalana, en particular de aquella parte de la burguesía que en el siglo XX habitaba en el Eixample, barrio en el que nació también la misma Roig. La autora indica que la redacción de Digues que m'estimes encara que sigui mentida finalizó en el año 1990; por otro lado, de acuerdo con la nota incluida en el tomo, unas primeras versiones, menos extensas, del ensayo "De finestres, balcons i galeries" se habían presentado anteriormente en los volúmenes colectivos Barcelona a vol d'ocell (1987) y Barceldones (1989). Esta disposición de las fechas deja abierta la cuestión si Montserrat Roig conocía la versión catalana del libro de Pizán antes de redactar o mientras redactaba su ensayo. Ciertamente, también podía haber leído el original de La Ciudad de las Damas u otra traducción - al francés moderno $^{2}$, al inglés...-. Sea como fuere, en el presente artículo no pretendo averiguar si su reflexión fue influida por la lectura del libro de Pizán ni, si fuera el caso, en qué

${ }^{1}$ La traducción castellana lleva el título La Ciudad de las Damas, pero en la introducción que acompaña el texto la traductora emplea también la forma "El Libro de la Ciudad de las Damas", más exacta y fiel al original (Pizán, 2006: 55). Sobre la historia de la recepción del libro de Cristina de Pizán en España, véase Godayol (2012: 173-175).

${ }^{2}$ La traducción catalana de Otero i Vidal se basa en esta versión moderna del libro, preparada por Moreau \& Hicks (Pizán, 1986). 
medida y en qué etapa de elaboración pudo producirse tal influencia. Me propongo leer el ensayo de Montserrat Roig para compaginar su representación de la ciudad de las mujeres (barcelonesas) con la visión "clásica" de Cristina de Pizán y, asimismo, poder observar los posibles puntos en común pero a la vez también las divergencias entre las dos creaciones, determinadas por diferentes circunstancias históricas que les sirvieron de contexto.

La Ciudad de las Damas, la obra maestra de Pizán, redactada a principios mismos del siglo $\mathrm{XV}^{3}$, es un relato de carácter alegórico. La narradora, que lleva el mismo nombre que la escritora - en el libro la autora aplica con habilidad los patrones y estratagemas de la escritura autobiográfica-, al haber expresado una profunda tristeza provocada por la lectura de un opúsculo misógino, recibe la visita de tres damas: Razón, Derechura y Justicia ${ }^{4}$. Estas figuras alegóricas le indicarán cómo construir una "ciudad de las damas", donde "[s]ólo [...] habitarán damas ilustres y mujeres dignas, porque aquellas que estén desprovistas de estas cualidades tendrán cerrado el recinto de nuestra Ciudad" (Pizán, 1995: 70). El proyecto de Pizán tiene, en definitiva, un carácter didáctico: la autora se propone aportar ejemplos de mujeres célebres, extraídos de diferentes campos de la cultura - a saber, la mitología, la historia de Francia y Europa, la historia y la tradición de la Iglesia, etc.- - que podrán servir a representantes del sexo femenino de "ciudadela donde defenderse contra tantos agresores", puesto que "[d]urante mucho tiempo las mujeres han quedado indefensas, abandonadas como un campo sin cerca, sin que ningún campeón luche en su ayuda" (Pizán, 2006: 69). Consciente de la inexistencia efectiva de la voz de la mujer en la historia y la cultura, provocada por el mutismo que a la mujer le habían impuesto la tradición y las prácticas culturales, y conociendo los males generados por esta falta, la escritora confecciona un repertorio de figuras femeninas ilustres por su coraje, sapiencia u honradez. La imagen de la ciudadela, la "plaza fuerte", "no sólo un refugio sino un baluarte para defenderos de los ataques de vuestros enemigos" (Pizán, 2006: 272-273), parece inspirarse en uno de los modelos que Pizán escogió a la hora de idear su texto, esto es, en La ciudad de Dios de San Agustín ${ }^{5}$. La intención didáctica de la obra de Pizán viene avalada por Le Livre des trois Vertus (o Le Trésor de la Cité des Dames), que la autora escribe directamente después de La Ciudad de las Damas ${ }^{6}$. El libro consta de una serie de discursos dirigidos, respectivamente, a mujeres de todos los estamentos con el objetivo de enseñarles cómo deberían actuar y vivir para poder ser contadas entre habitantes de la ciudad de las damas "levantada" en el libro anterior? . Asimismo,

${ }^{3}$ Hicks y Moreau (Pizán, 1986: 31) sitúan su redacción entre el 13 de diciembre de 1404 y abril de 1405 .

${ }^{4}$ Sigo la traducción castellana (Pizán, 1995).

${ }^{5}$ Sobre este aspecto véase, por ejemplo, Zhang (2004).

${ }^{6}$ Entre la primavera 1405 y el 7 de noviembre del mismo año, según Hicks y Moreau (Pizán, 1986: 31).

${ }^{7}$ La relación de continuidad entre los dos libros es evidente. En Le Livre des trois Vertus, Razón, Derechura y Justicia vuelven a visitar a Cristina—narradora y la exhortan a no sucumbir 
queda patente el doble carácter del proyecto de Pizán: por un lado, sus enseñanzas se dirigen a las mujeres de su tiempo y de la sociedad que la escritora conoce y de la que forma parte; en este sentido los dos libros, no obstante el modelo alegórico manifiesto en la visita de las tres Damas, presentan unos contenidos que es imposible disociar del momento histórico en el que fueron formulados. Por otra parte, la autora deja abiertas las puertas de su ciudad a las mujeres de todos los países y a las que vendrán en el futuro; asimismo, le otorga a su construcción la capacidad de resistir la prueba del tiempo y el espacio al considerar sus consejos aplicables en diferentes contextos históricos, sociales y geográficos. En definitiva, el conjunto de virtudes recomendado por Cristina de Pizán se presenta como modelo de conducta universal:

Excelentes y honorables princesas de Francia y de todos los países, vosotras, damas, doncellas, mujeres de todas las condiciones que amasteis o amáis y seguiréis amando el bien y la sabiduría, las que habéis muerto, las que vivís todavía y las que vendréis en el futuro, alegraos todas, disfrutad de esta nueva Ciudad, que ya está casi toda levantada, construidos sus harmoniosos edificios y reunidas ya quienes en ella vivirán (Pizán, 2006: 248-249).

Montserrat Roig, por su parte, aprovecha la libertad que le ofrece el género ensayístico para entrelazar la historia de su ciudad con su biografía personal. Presenta una visión de la historia de Barcelona tamizada por su propia experiencia y sus vivencias, e inspirada por sus lecturas ${ }^{8}$. La Barcelona del ensayo "De finestres, balcons i galeries", más que "ciudad de las damas", es "ciudad de las mujeres". Si bien es verdad que Cristina de Pizán invita a su fortaleza a las "mujeres de todas las condiciones", el rasgo que, en definitiva, garantiza el derecho de entrada al recinto es la nobleza de espíritu, que deriva del ejercicio de una serie de virtudes que deben lucir las mujeres. Esta nobleza las convierte en "damas", independientemente de su condición social. Montserrat Roig, por su parte, se imagina a diferentes figuras femeninas que han mirado la ciudad, entre las cuales encontramos, ciertamente, también a una mujer de capas altas de la sociedad: "No és una dona de mercader, o una menestrala, repenjada

a la pereza y a continuar instruyendo a las mujeres. En su discurso las damas emplean un - curioso desde el punto de vista del lector actual - imaginario cinegético (jaulas, red, etc.) dando a entender que las instrucciones aportadas por Cristina e inspiradas por ellas mismas, deben atraer con señuelo y capturar a las mujeres para que éstas puedan adquirir el derecho de habitar en la ciudad de las damas: " À la façon de l'habile oiseleur qui prépare la cage avant de capturer les petits oiseaux, maintenant que la demeure des nobles dames est construite et aménagée, nous voulons avoir ton aide comme la première fois, pour prévoir et préparer pièges, trébuchets et filets : beaux et riches, ils seront ornés de nœuds d'amour que nous te procurerons. [...] Notre enseignement s'adressera donc d'abord aux reines, princesses et nobles dames, et ensuite, en descendant de degré en degré, nous reprendrons pareillement notre enseignement pour les femmes de toutes les conditions, afin que les connaissances procurées par notre école puissent convenir à toutes » (Pizán, 2006: 561-562). Utilizo el nombre "Cristina" ( $\sin$ apellido) cada vez que me refiero a la narradora y protagonista del relato pizaniano.

${ }^{8}$ En particular, La vida quotidiana a Barcelona vers 1400 de Teresa-Maria Vinyoles i Vidal (Barcelona, Rafael Dalmau, 1985), un estudio histórico que la escritora cita como una suerte de "guía" en sus viajes por el pasado de la ciudad. 
a l'ampit d'una finestra gòtica, sinó una dama que somnia des d'un balcó d'una casa, mig flamígera mig renaixentista" (1991: 129). Pero si el libro de Pizán pretende formar una suerte de "elite" de mujeres — que podrán morar en la ciudad de las damasesta idea no se evidencia en el proyecto de Roig. La Barcelona de sus ensayos no es una construcción alegórica sino recreación personal y literaria de una ciudad real e histórica, que vivía y se transformaba junto con sus habitantes (femeninos, en este caso). Las preferencias de la autora parecen reflejarse incluso en las fórmulas semánticas que escoge. En el artículo de Avui citado anteriormente, a la hora de referirse a la traducción catalana de la obra de Pizán, Roig menciona, lógicamente, su título, La ciutat de les dames, pero cuando pasa a caracterizar el proyecto pizaniano prefiere hablar de una "ciutat per a les dones" (ciudad para las mujeres). La suya es, pues, una ciudad histórica de "todas" las mujeres que en ella han habitado y que a través de sus miradas han contribuido a su historia.

No obstante esta y otras diferencias (algunas de las cuales comentaré a continuación) en la manera de relacionar el tema de la ciudad y el de la mujer, diferencias derivadas de las circunstancias históricas en las que escriben las autoras o de las soluciones genéricas e ideológicas que aplican respectivamente, las visiones de Pizán y Roig tienen también puntos en común importantes. Entre ellos, un aspecto de mayor interés es la relación entre la experiencia de la ciudad y el proceso de escritura.

Como se ha dicho, en La Ciudad de las Damas Cristina de Pizán desea cumplir el papel de transmisora - si no de fundadora - de la tradición femenina en la cultura. La ciudadela alegórica que pretende edificar servirá de amparo a las que por sus propias fuerza e iniciativa deben protegerse de los ataques contra su sexo. Las palabras pronunciadas por las Damas expresan el orgullo que a la narradora del libro le inspira su misión:

Tú serás la elegida para edificar y cerrar, con nuestro consejo y ayuda, el recinto de tan fuerte ciudadela (Pizán, 2006: 70).

Así, querida hija, sobre ti entre todas las mujeres recae el privilegio de edificar y levantar la Ciudad de las Damas (Pizán 2006: 70) ${ }^{9}$.

La narradora es entonces la "constructora" de la ciudad, la que llevará a cabo la labor de su fundación. Y observemos enseguida que el valor figurado que adquiere el trabajo de edificar no se reduce a la presentación de las figuras señeras de esa narración a la cual la escritora desea otorgar el rango de la tradición femenina universal. Ciertamente, de acuerdo con la fórmula alegórica adoptada, el levantamiento de la ciudad "visualiza" la presencia femenina en la cultura, pero, a la vez, su sentido es más amplio y profundo. Pues, gracias a una serie de procedimientos aplicados con

${ }^{9}$ Este mismo orgullo se manifiesta en las palabras con las que la escritora se refiere a otras obras suyas: "Tú misma lo has dicho muy bien en alguno de tus escritos: no es a las mujeres a las que hay que acusar si hay locos que abusan de ellas [...]. Tú lo has dicho muy bien en alguna parte [...]” (Pizán, 2006: 76). 
ingeniosidad y sutileza, en el libro de Pizán la construcción de "fortificaciones y pesadas puertas" (2006: 73) llega a representar el proceso de escritura, o, si preferimos, la ciudad que edifica la autora del libro es, en definitiva, texto.

Para entender mejor este proceso de levantar la ciudad que es a la vez el de escribir observemos unas relaciones cronotópicas instauradas en el relato ${ }^{10}$. El texto de $L a$ Ciudad de las Damas, en su parte inicial, establece diferentes niveles espacio-temporales. El primero está constituido por el tiempo y el espacio de la enunciación: Cristina-narradora, instalada en su "aquí y ahora", evoca y describe los acontecimientos que hubieran tenido lugar en el pasado. La información sobre el "aquí y ahora" es muy limitada, por no decir nula, y siempre indirecta. El lector no dispone, por ejemplo, de los datos concernientes al espacio de la enunciación — no llega a enterarse dónde ha sido redactado el informe de la visita de las tres Damas - pero se imagina que el acto de escritura se ha realizado en el mismo cuarto de estudio donde se había iniciado la serie de hechos evocados en la narración. Un segundo nivel cronotópico está constituido por el tiempo y el espacio —o más propiamente dicho, los espacios- de la diégesis. La secuencia temporal se inicia el día en el que, "[s]entada [...] en [su] cuarto de estudio, rodeada [...] de los libros más dispares" (Pizán, 2006: 63), Cristina-personaje se pone a leer el Libro de las lamentaciones de Mateolo; al día siguiente, cuando, por la mañana, retoma la lectura del libro y el hilo de sus reflexiones, aparecen las tres Damas y empieza la fundación de la ciudad. A este tiempo le corresponden dos espacios: el cuarto de estudio, lugar de visita de las Damas, y el espacio alegórico del Campo de las Letras adonde se dirige Cristina-personaje en compañía de las Damas. Es aquí donde se van a realizar las obras de la construcción ${ }^{11}$.

Dicho esto, veamos algunas características de la estrategia narrativa empleada en La Ciudad de las Damas. Al comienzo del capítulo octavo del primer libro Dama Razón invita a Cristina-personaje a dirigirse hacia el lugar donde la ciudad será construida, diciendo: “iLevántate, hija mía! Salgamos sin tardanza hacia el Campo de las Letras. Es allí, en aquel país rico y fértil, donde será fundada la Ciudad de las Damas. [...] Coge la azada de tu inteligencia y cava hondo" (Pizán, 2006: 75). A partir de este momento el lector del libro sabe que la ciudad que se fundará en este sitio será una "ciudad de letras", una ciudad cuyas piedras serán las palabras. El proceso de construcción comienza en el acto y avanza con cada pregunta que Cristina pone a las Damas: "Ella me precedió para guiarme hasta el Campo de las Letras, y siguiendo sus indicaciones, me puse a cavar el foso interrogando con la azada de la inteligencia" (Pizán, 2006: 75) ${ }^{12}$, dice la protagonista. El concepto de "letra" que

${ }^{10}$ Algunos de los contenidos concernientes a la estructura cronotópica del relato en La Ciudad de las Damas y a su relación con el tema de la escritura los presenté en forma de comunicación en el "VIII Colloque International Christine de Pizan" (Poznań, 10-14 de julio de 2012).

11 Finalmente, podría distinguirse también un tercer nivel cronotópico, constituido por los tiempos y los espacios de acción de diferentes historias protagonizadas por mujeres célebres, que las tres Damas cuentan a Cristina.

${ }^{12}$ La versión en francés moderno es incluso más explícita en este pasaje, pues se refiere a la interrogación como al instrumento que hará posible el levantamiento de la ciudad: "Elle me précéda 
encontramos en la denominación de aquel espacio en el que se realizarán las obras nos proyecta, inevitablemente, hacia el dominio de la escritura: la letra es, pues, signo gráfico. Esto nos permite entender el sentido - o los diferentes sentidos - que adquiere la imagen de esa fortaleza. De entrada, podemos constatar que la ciudad de Pizán está fundada en el Campo de las Letras porque las historias que las tres Damas cuentan a Cristina-personaje están extraídas del dominio de las escrituras. El hecho que la construcción se realice en el Campo de las Letras indicaría, entonces, el tipo de "material" que será utilizado en esta fundación, un material que, en este caso, son referencias y ejemplos tomados de la tradición escrita.

Ahora bien, por otra parte no cabe duda que un elemento de mayor importancia en aquel levantamiento de la ciudad es el trabajo — de albañilería, se diría para destacar la labor de erigir, piedra por piedra, los muros de la fortaleza - cuyo agente principal es Cristina. La construcción tiene carácter alegórico ya que representa el proceso de escritura realizado por Cristina-narradora. Cada nueva "piedra" que Cristina coloca en la construcción añade un elemento nuevo al relato o, a la inversa, cada historia de un personaje femenino incluida en el relato eleva un poco más los muros de la ciudadela ${ }^{13}$. En este contexto vale la pena enfatizar un aspecto más que nos hace admirar la forma magistral en la que la autora aprovecha las características del relato autobiográfico. Cristina escucha los discursos de las tres Damas y construye la ciudad siguiendo sus sabios consejos e instrucciones. La actitud de recepción que adopta es igualmente interesante que el proceso de creación, esto es, la acción de escribir. No olvidemos que en su trabajo Cristina-personaje emplea como instrumento "la azada de la interrogación" (sigo la versión francesa). En efecto, su discurso adopta la forma de una lección recibida "de la boca" de las tres Damas ${ }^{14}$. De esta forma, la construcción de la ciudad llega a representar, como se ha dicho, el trabajo de escritura pero también el proceso de aprendizaje de la protagonista; es importante subrayar, en este sentido, que entre las tres Damas y Cristina se establezca la relación maestra(s) - discípula. Las Damas cuentan y Cristina aprende y, a la vez, construye la ciudad, esto es, escribe su texto. De esta forma, recurriendo a la alegoría de la construcción de la ciudad, la autora consigue presentar de manera simultánea dos acciones - el aprendizaje

pour me conduire audit champ, et je me mis, suivant ses indications, à creuser la fosse avec ma pioche d'Interrogation" (Pizán, 1986: 48).

${ }^{13} \mathrm{Y}$ observemos enseguida que esta constatación hace replantear la distinción entre el tiempo-espacio de la enunciación y el de la diégesis, y, en consecuencia, la distinción entre Cristina-narradora y Cristina-personaje, constituidas inicialmente por el texto. El proceso de escritura se sitúa entre los dos niveles: Cristina-narradora redacta su informe separada por una distancia temporal de los sucesos que cuenta, pero a la vez, la misma acción de escribir — representada por la construcción de la Ciudad- está integrada en el nivel de la diégesis. Gracias a esta conjunción de los dos niveles, el relato adquiere un carácter autorreferencial.

${ }^{14}$ En el texto encontramos toda un serie de fórmulas que acentúan el carácter oral de esta transmisión de conocimientos: "Decís verdad, Dama mía, y mi mente se complace en escucharos" (Pizán, 2006: 91); "Como lo oirás ahora" (Pizán, 2006: 99); "Después de oír esas historias, yo pregunté a la Dama que hablaba con tan firme discurso" (Pizán, 2006: 118), etc. 
y la escritura - que, desde el punto de vista lógico, no deberían realizarse al mismo tiempo, siendo el aprendizaje anterior a la escritura ${ }^{15}$. Este procedimiento le permite mostrar otro proceso que es el de la construcción de su propia identidad. Aprendiendo y redactando su texto, Cristina de Pizán construye los "muros" de su propia identidad como mujer, como escritora, como mujer-escritora, a fin de cuentas. En este sentido, creo, es lícito leer La Ciudad de las Damas como un relato de autoformación. Edificar la ciudad, piedra tras piedra, una palabra tras otra, es, ante todo, realizar y contar el proceso de su propia construcción, la construcción de un sujeto que busca modelos alternativos respecto a los preconizados, o incluso sacralizados, por la sociedad y la cultura ${ }^{16}$.

La ciudad "fundada" en el libro de Pizán se caracteriza por una transparencia, proporción perfecta y homogeneidad propias de una creación alegórica. La Barcelona de los ensayos de Roig, por su parte, se distingue por una riqueza abigarrada y multiforme de la urbe histórica. No obstante, en los textos reunidos en Digues que m'estimes encara que sigui mentida encontramos diferentes elementos que, aunque en definitiva servirán para presentar una experiencia de la ciudad concreta, personalmente vivida e históricamente reconocible, no por eso dejan de recordar la construcción pizaniana. "De finestres, balcons i galeries" se cierra con estas palabras, que resuenan como el postrer acorde del volumen:

Per a escriure ens hem de sentir, alguna vegada, expulsats. I la ciutat actual, com totes les ciutats actuals, expulsen els qui la narren. I això és bo: perquè hi retornes després, d'una altra manera. Aleshores sí, aleshores pots construir una ciutat, diferent i semblant a la vida, que és la ciutat literària (Roig, 1991: 169).

Como la fortaleza de Pizán, la Barcelona de los ensayos de Roig, en palabras de la propia autora, es, obviamente, una "ciudad literaria", esto es, una ciudad "escrita", fundada con palabras. También el impulso que lleva a la autora catalana a realizar esta obra de fundación trae a la mente el punto de arranque de la reflexión de la escritora francesa. Roig deplora la inexistencia de la tradición femenina en la práctica de describir y experimentar la ciudad considerada como espacio público, un espacio de cultura. "La autora construye una historia de Barcelona desde la Edad

${ }^{15}$ Dulac recuerda que en diferentes ocasiones Cristina de Pizán se sirve de la locución patrística "campo de escrituras" para unir dos aspectos: recolección (de frutas) y producción. Y continúa constatando que en La Ciudad de las Damas, el campo es a la vez « un verger délicieux et un chantier, le lieu d'une grande entreprise de construction » (2008: 202). Esta dualidad llega a representar la conjunción del proceso de aprendizaje con el de escritura.

${ }^{16}$ Y recuerdo una vez más que, en el relato pizaniano, el impulso para la escritura es la lectura del Libro de las lamentaciones de Mateolo, caracterizado como un extraño opúsculo, que no era mío sino que alguien me lo había prestado" (Pizán, 2006: 63). La versión francesa moderna es incluso más contundente: la narradora explicita que este libro « ne m'appartenait pas, mais [...] avait été pour ainsi dire laissé en dépôt chez moi par un tiers » (Pizán, 1986: 35). La falta de confianza que la narradora ostenta respecto al libro y a la tradición que éste propone, una tradición legada por algún "tercero", "otro", no podría ser más evidente. 
Media hasta la década de los ochenta [del] siglo [XX], a partir del avance espacial de sus ciudadanas, quienes, lamentablemente, no han dejado ninguna huella escrita de sus vidas", dirá Dupláa (1996: 145). La mujer, a quien ha sido negada la palabra, no ha podido pronunciarse sobre la historia de su ciudad, de su país y sobre su propia historia, puesto que sus reflexiones en ningún momento han pasado el umbral de lo íntimo y privado. En este sentido, Roig llega a considerar la mirada como un instrumento femenino por excelencia - por ser el único accesible- de conocer y vivir la ciudad durante muchos siglos: "[V]aig començar a imaginar-me totes aquelles mirades de dones [...]" (Roig, 123-124). Obviamente, la actividad de mirar a la que pudieron dedicarse la mujer del siglo XIV y sus seguidoras en ningún momento debe ser relacionada con una suerte de flânerie avant la lettre, esto es, una práctica desinteresada ejercitada por un sujeto que se desenvuelve libremente en el espacio urbano. Primero, porque el sujeto femenino no ha sido autorizado a participar de pleno derecho en el espacio público (Wolff [1985] y Pollock [1988: 66-67] arguyeron, ya tiempo atrás, que el equivalente femenino del flâneur no existió ni pudo existir). Luego, porque en la presentación de la escritora catalana, la mirada — una forma de conocimiento que lleva implícita la mudez que caracteriza la experiencia del sujeto femenino - está sometida a constreñimientos de otro tipo. Las ventanas, los balcones y las galerías, que aparecen en el título del ensayo, son "marcos" a través de los cuales la mujer, a quien la tradición ha confinado en gran medida en el hogar familiar, ha ido tomando conocimiento del mundo. Estos elementos arquitectónicos, que al caracterizar su entorno físico limitan su campo de visión, pueden llegar a representar, metonímicamente, todo tipo de limitaciones que la cultura ha impuesto sobre el sujeto femenino:

La ciutat $[. .$.$] ha anat oferint a les dones durant segles diversos radis de visió contruïts amb figu-$ res geomètriques. Les dones han vist el món rodó, rectangular o quadrat. De vegades eren unes línies paral·leles, estretes, que acabaven a la fäbrica. [...] Dama, senyora, menestrala o xinxa: el camp de visió variava una mica però [...] l'actitud de mirar les unia (Roig, 1992: 155).

La historia, entonces, ha privado a las habitantes de la ciudad de la posibilidad de tomar, pronunciar y sonorizar la palabra, y mucho más, de trasmitirla en forma escrita. El texto repetidas veces subraya la falta de la palabra escrita legada por la mujer: "Per a saber com han estat les cases, els interiors, ens caldrien més memòries escrites per dones" (1992: 123); "durant segles, moltes dones, [...] mai no han pensat, a causa de les regles estrictes de la història social de la literatura, que la seva curiositat podia esdevenir obra escrita, i a voltes art" (1992: 123); “El seu home veu el món. Ella se l'imagina a través de la finestra. Però no l'escriu" (1991: 128), etc. Y recordemos que el tema de la palabra femenina, de la posesión de la palabra por la mujer, fue el aspecto que Roig evocaba en el libro de Pizán, en el artículo publicado en Avui. La primera parte del ensayo se cierra con la siguiente constatación: "Era una mirada que encara no havia trobat les paraules, les seves, per a expressar allò que veia. I és això el que li falta a la història de Barcelona. I a la seva literatura” (Roig, 1991: 155). 
A continuación, en "Barcelona, una geografia literària", la escritora da a conocer algunos detalles de su propia formación artística. Al pasar directamente de la primera sección a la segunda, el lector llega a tratar la anécdota personal de la autora como prolongación y complemento de la experiencia femenina de la ciudad presentada anteriormente y a considerar la labor literaria de Roig como reacción a aquella inexistencia de la voz de la mujer que ella denunciaba en la historia de Barcelona. Efectivamente, la escritora parece incluirse a sí misma en aquella nómina de mujeres que durante siglos han ido mirando la ciudad, una nómina que ella ha conformado en el apartado anterior. Asimismo, en la parte final del ensayo volvemos a encontrar la poética de los espacios cerrados ya evocada: la Barcelona de la infancia de Roig, como la de sus predecesoras, se compone de una serie de espacios cerrados: el patio familiar, el patio del colegio de monjas... Su experiencia de la ciudad está marcada por recintos que, como ventanas góticas o balcones de casas renacentistas, procuraban un campo de visión limitado. Con una diferencia empero: ella sí escribe.

Presentándose como una de las mujeres que durante siglos han contemplado Barcelona, pero a la vez destacando el carácter excepcional de su situación, que deriva de su oficio de escritora, Roig, como Pizán, puede abordar el tema de la memoria y de la tradición femenina ${ }^{17}$ y vincularlo con la problemática de la ciudad. Con la diferencia de que la autora francesa fundaba esta tradición en una serie de figuras femeninas célebres, destacando su carácter extraordinario (véase también Zimmermann, 2002: 928-929), mientras que la escritora catalana se refiere a mujeres anónimas tratándolas como tipos representativos. Roig se considera como heredera y continuadora de la línea femenina de las "lectoras" de la ciudad; a la vez, es una de las mujeres que finalmente han podido y sabido sobreponerse a las limitaciones que apenaban a sus madres, abuelas y tatarabuelas, dejando constancia escrita de lo que han visto y vivido ${ }^{18}$. En este contexto se entiende por qué en la primera parte del ensayo la autora ha procurado sonorizar las voces de las mujeres que habían habitado en Barcelona. Roig pretende desempeñar el papel de "escribiente", para vestir de palabras la tradición femenina de experimentar el espacio urbano, una tradición manifiesta en la continuidad de la mirada, hasta ahora muda, frágil y voladiza. De esta forma, le asegura duración. "[L]a ciutat és plena de pedres que ja no hi són, murs invisibles esfondrats físicament, plena de veus que no trobaren una escriptura per a fer-les perdurar. Només existeix allò que ha estat escrit. [...] Jo sentia aquestes veus sense escriptura, a casa, al carrer" (Roig, 1991: 166). Sonorizar las lecturas femeninas del espacio urbano significa también salvar una importante parte de la cultura y la historia de la ciudad: "[V]aig començar a imaginar-me totes

${ }^{17}$ El tema de la memoria y la tradición femenina es uno de los principales temas de la obra de Montserrat Roig, que vertebra su creación novelística, en particular la trilogía formada por Ramona, adéu (1972), El temps de les cireres (1977) y L'hora violeta (1980).

18 Picornell constata "[E]ls testimonis, tot i que parteixin de records individuals, podrien ampliar metonímicament el seu abast per tal d'incloure la memòria dels individus que són afins en la vivència d'aquests esdeveniments" (2002: 106). 
aquelles mirades de dones, la percepció visual de les quals a penes si ens ha deixat algun rastre. D'aquesta manera, les ciutats perden part de la seva història, de la seva memòria" (Roig, 1991: 123-124).

Dando voz y letra a las miradas femeninas que han contemplado el espacio de Barcelona la escritora otorga a la ciudad el estatus de texto, susceptible a ser leído e interpretado. Bajo miradas atentas, el texto urbano desvela sus sentidos y la escritora asume la responsabilidad de recuperar estas lecturas, considerándolas en los contextos sociales e históricos concretos que les corresponden. Pero el ensayo establece también otra relación entre ciudad y texto. Roig contempla el espacio urbano "saturado" de una multitud de miradas que en él han quedado impresas y - cual una arqueóloga - las va descubriendo capa tras capa, mirada tras mirada. Esta práctica revela una naturaleza palimpséstica del espacio urbano conceptuado como texto: Si cada una de las lecturas femeninas lleva en sí un sentido particular e irrepetible, vistas en conjunto conforman una parte de la historia de la ciudad que la ensayista se propone recuperar. En esta circunstancia, la lectura y exégesis del palimpsesto urbano debe adquirir rasgos de una "radiografía", capaz de percibir la diversidad de las miradas inscritas pero a la vez de tomar en cuenta una dimensión temporal de este corpus, al considerar su superposición y su evolución originada por cambios históricos.

La nobleza de espíritu que debían lucir las damas para garantizarse el acceso a la ciudadela otorgaba a la ciudad pizaniana una homogeneidad y universalidad que favorecían una lectura panorámica y sincrónica. Por su parte, la Barcelona de la visión diacrónica de la autora catalana es una ciudad dividida en parcelas, adscritas a diferentes grupos de mujeres, que miran la ciudad desde espacios distintos y este punto de vista determina su manera de experimentar la urbe. Esto, en definitiva, me parece la diferencia más importante entre las dos construcciones. En el ensayo de Roig, la Barcelona de la mujer medieval no es igual a la de la dama renacentista y la ciudad de la "chinche" está en las antípodas de la de la burguesa del Eixample. El único elemento que vincula a estos sujetos femeninos es el ejercicio de mirar una misma ciudad. Sus visiones del espacio urbano son una lecturas ideológicas, determinadas por el fondo social. Otros ensayos incluidos en Digues que m'estimes encara que sigui mentida otorgan a la heterogeneidad espacial de Barcelona una dimensión nueva, la lingüística. Las parcelas de la ciudad, habitadas por grupos sociales distintos, también se caracterizan por lenguajes diferentes. A la escritora, cuando niña, la heterogeneidad de la urbe se le revela en la multiplicidad de lenguajes utilizados en espacios y ambientes diversos: "Els pobres de l'escala podien jugar al carrer, podien dir paraulotes, podien dir mots que feien «pagès», com «guaita» per mira i «got» per vas" ("Les coses mai no van ser així", Roig, 1991: 50). Otra característica de la Barcelona de Roig — que la arraiga fuertemente en su contexto socio-histórico y la aleja, asimismo, de la ciudad universal de Pizán — es la relación entre el espacio y la lengua propia, la lengua materna, la lengua catalana. En sus recuerdos de la infancia transcurrida en el período franquista, la diversidad de espacios y lenguajes 
adquiere esta evidente dimensión ideológica y nacional: "La llengua del poder era representada per l'habitacle tancat del convent de monges, la llengua per la qual havíem de lluitar era també un pati tancat, encara que fos a casa" ("Un teló de vellut negre"; Roig, 1991: 38) ${ }^{19}$.

La ciudad es fruto de una ilusión. Nace del sueño de coexistencia y convivencia posibles, de un destino compartido, feliz y armónico. Estas ideas debían acompañarle a Cristina de Pizán, cuando piedra tras piedra, historia tras historia, levantaba los muros de su ciudadela-texto detrás de los cuales encontrarían refugio y amparo las mujeres nobles de espíritu de todos los países y épocas. La escritora francesa proyectó su ciudad alegórica hacia los tiempos venideros y espacios desconocidos. Montserrat Roig, por su parte, se propuso rescatar unas parcelas del pasado acontecido en un espacio concreto y familiar para otorgarle continuidad en el presente. Su visión no tiene la ambición de aportar soluciones universales; al contrario, su interés reside en salvar unas Barcelonas particulares, vistas por diferentes mujeres, unas Barcelonas tan individuales e irrepetibles como la suya. Propone entonces reconocer e incorporar en la historia de la ciudad todas aquella miradas femeninas, hasta ahora mudas, y aceptar su diversidad e unicidad irreductibles. No obstante - y no sé si es paradójico $\mathrm{o}$, por el contrario, inherente a la experiencia femenina de la urbe - la reflexión que cierra los ensayos de Roig, citada arriba, se asemeja a la que dio pie a la redacción del libro de Pizán. Para la autora catalana la expulsión de la ciudad —una ciudad histórica y real- es un impulso para regresar a su recinto de manera diferente y transfigurarlo en una ciudad literaria. Curiosamente, varios siglos atrás, en un París gris o asoleado, Cristina de Pizán leyó un día el Libro de las lamentaciones de Mateolo y también se sintió expulsada de una ciudad, la que representaba la cultura de la sociedad que le fue contemporánea.

\section{BIBLIOGRAFÍA}

Dulac, Liliane (2008): « De l'arbre au jardin, de la pastorale à la politique : quelques transpositions métaphoriques et allégoriques chez Christine Pizan ». In: Liliane Dulac et al. [ed.], Desireuse de plus avant enquerre... Actes du VI Colloque international sur Christine de Pizan (Paris, 20-24 juillet 2006). París: Honoré Champion, 191-208.

DupláA, Cristina (1996): La voz testimonial en Montserrat Roig. Estudio cultural de los textos. Barcelona: Icaria.

Godayol, Pilar (2012): "La ciutat de les dames i Terra d'elles: dues utopies feministes en català". Quaderns 19: 169-182.

ŁUCZAK, Barbara (2004): "Mirant l'Eixample, tot eixamplant la mirada: apuntes sobre la mirada urbana en las letras catalanas contemporáneas". In: Roland Spiller y Yvette Sánchez [ed.], La poética de la mirada. Madrid: Visor Libros, 155-165.

Picornell Belenguer, Mercè (2002): Discursos testimonials en la literatura catalana recent (Montserrat Roig i Teresa Pàmies). Barcelona: Publicacions de l'Abadia de Montserrat.

19 Abordé este tema en Łuczak (2004: 158). 
Puzán, Cristina de (1986): Le Livre de la Cité des Dames, trad. (al francés moderno) Éric Hicks y Thérèse Moreau. París: Stock.

- (1990): La Ciutat de les Dames, trad. Mercè Otero i Vidal. Barcelona: Edicions de l'Eixample.

- (1995): La Ciudad de las Damas, trad. Marie-José Lemarchand. Madrid: Siruela.

- (2006): Le Libre des trois Vertus. In: Danielle Regnier-Bohler, Voix de femmes au Moyen Âge. Savoir, mystique, poésie, amour, sorcellerie. XII à XV'siècle, trad. (al francés moderno) Liliane Dulac. París: Lafont, 541-698.

Pollock, Griselda (1988): Vision and Difference. Feminity, Feminism and Histories of Art. Londres - Nueva York: Routledge.

RoIG, Montserrat (1991): Digues que m'estimes encara que sigui mentida. Sobre el plaer solitari d'escriure i el vici compartit de llegir. Barcelona: Edicions 62.

- (1992): Un pensament de sal, un pessic de pebre. Dietari obert 1990-1991. Barcelona: Edicions 62.

WoLfF, Janet (1985): "The Invisible Flâneuse: Women and the Literature of Modernity". Theory, Culture and Society 2, 3: 37-48.

Zhang, Xiangyun (2004): "L'idée de "deux cités". L'influence de saint Augustin sur Christine de Pizan ». Cahier de recherches médiévales et humanistes, 11 (spécial): 121-132. URL: <http:// crm.revues.org/2082> (consulta: 6.04.2013).

Zimmermann, Margarete (2002): "Christine de Pizan ou la memoria au féminin ». In: Angus J. Kennedy et al. [ed.], Contexts and Continuities. Proceedings of the IVth International Colloquium on Christine de Pizan (Glasgow 21-27 July 2000), published in honour of Liliane Dulac, vol. III. Glasgow: University of Glasgow Press, 919-930. 